ADDENDUM-Since this paper was accepted for publication a report of a prospective randomised clinical trial comparing the effects of somatostatin and vasopressin in the control of acute variceal haemorrhage has been published (Kravetz D, Bosch J, Teres J, Bruix J, Rimola A, Rodes J. Comparison of intravenous somatostatin and vasopressin infusion in the treatment of acute variceal haemorrhage. Hepatology 1984;4:442-6). There was no difference in the effectiveness of somatostatin and vasopressin in controlling variceal haemorrhage, but administration of somatostatin was associated with fewer complications. The two trials are not, however, strictly comparable because of differences, to which we have drawn attention (Hepatology, in press), in the mode of administration of somatostatin and vasopressin.

\section{References}

1 Kehne JH, Hughes FA, Gompertz ML. The use of pituitrin in the control of esophageal varices: an experimental study and report of two cases. Surgery

2 Conn HO, Dalessio DJ. Multiple infusions of posterior pituitary extract in the treatment of bleeding oesophageal varices. Ann Intern Med 1962;57:804-9. hnson WC, Widrich $W$, Ansell $\mathrm{JE}$, et al. Control of bleeding varices by

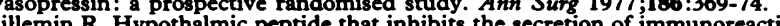
pituitary owth hormone. Science 1973;179:77-9.

Wahren J, Felig P. Influence of somatostatin on carbohydrate disposal and absorption in diabetes mellitus. Lancet $1976 ;$ ii :1213-6.

Bloom SR. Somatostatin and the gut. Gastroenterology 1978;75:145-7.

Bloom SR, Mortimer Ch, Thorner MO, et al. Inhibition of gastrin and gastric acid secretion by growth hormone release-inhibiting hormone. Lancet 1974;
8 Gomez-Pan A, Reed JD, Albinus M, et al. Direct inhibition of gastric acid and pepsin secretion by growth hormone release-inhibiting hormone in the cat.

9 Raptis S, Schlegel W, Lehmann E, et al. Effects of somatostatin on the exocrine pancreas and the release of duodenal hormones. Metabolism 1978;27(suppl 1):

0 Samnegard $\mathrm{H}$, Thulin $\mathrm{L}$, Andreen $\mathrm{M}$, et al. Circulatory effects of somatostatin on anaesthetised dogs. Acta Chir Scand 1979;145:209-12

11 Tyden G, Samnegard $H$, Thulin $L$, et al. Treatment of bleeding oesophageal varices with somatostatin. $N$ Engl $f$ Med 1978;299:1466-7.

12 Child CG, Turcotte JG. Surgery and portal hypertension. In: Child CG, Dunphy $\mathrm{JE}$, eds. Major problems in clinical surgery: the liver and portal hypertension. Vol 1. Philadelphia: WB Saunders, 1964:1-85

13 Anonymous. Bleeding oesophageal varices [Editorial]. Lancet 1984;i:139-41.

4 Basso N, Bagarani M, Quondamcarlo C, et al. Effective control of variceal bleeding by somatostatin: a double-blind, randomized, cross-over study. Gastroenterology 1983;84:100.

15 Raptis S, Zoupas C. Somatostatin not helpful in bleeding esophageal varices. Engl f Med 1979;300:736-7.

16 Jenkins SA, Devitt $P$, Shields $R$. The effect of somatostatin on hepatic haemodynamics in the cirrhotic rat. Langenbecks Arch Chir 1982;357:117-8.

17 Bosch J, Kravetz D, Rodés J. Effects of somatostatin on hepatic and systemic haemodynamics in patients with cirrhosis of the liver and in normal subjects. Gastroenterology 1981;80:526-32.

18 Konturek SJ, Tasler J, Cieszkowski M, et al. Effect of growth hormone releaseinhibiting hormone on gastric secretion, mucosal blood flow, and serum gastrin. Gastroenterology 1976;70:737-41.

19 Sonnenberg GE, Keller V, Ferruchoud A, et al. Effect of somatostatin on planchnic haemodynamics in patients with cirrhosis of the liver: comparison rology $1981 ; 80: 518-25$.

20 Parbhoo $S$. The management of bleeding in liver disease. Br 7 Hosp Med 1975; $15: 17-28$.

21 Kayasseh L, Gyr K, Keller V, et al. Somatostatin and cimetidine in peptic-ulcer haemorrhage. Lancet 1980 ; i:844-6.

22 Bringer J, Dubois A, Richard JL, et al. Effets de la somatostatine dans les hemorragies oesophagiennes. Une observation d'oesophagite ulcerce. Nouv Presse Med 1980;17:1225-7.

23 Bosch J, Kravetz D, Terres J, et al. A controlled comparison of continuous (treatment of acute variceal haemorrhage. Hepatology 1982;2:707.

(Accepted 23 October 1984)

$\underline{\underline{\underline{T}}}$

\title{
Height at diagnosis of diabetes in children: a study in identical twins
}

\author{
P J HOSKINS, R D G LESLIE, D A PYKE
}

\begin{abstract}
The height at diagnosis of 16 insulin dependent diabetics aged under 19 was compared with that of their unaffected identical cotwins measured at the same time. In eight pairs the diabetic was shorter, and in the remainder the cotwins were the same height. In those diabetics who were shorter than their cotwins at diagnosis the average period of growth delay before diagnosis was at least 35 weeks; by contrast, the mean duration of symptoms was only six weeks. No cause for the growth delay other than the diabetes was known in any of the twins.

These findings show that the onset of insulin dependent diabetes may be a slow process, with growth delay occurring several months before symptoms appear.
\end{abstract}

\section{Introduction}

Growth is a sensitive indicator of health in childhood. Uncontrolled diabetes retards growth: before the discovery of insulin growth stopped completely in children who developed diabetes. ${ }^{1}$ We have used these observations to determine whether diabetes can be present, as shown by growth delay, before the appearance of symptoms.

Studies of heights at diagnosis in diabetic children have produced conflicting results. In most the diabetics were found to be taller than expected, ${ }^{2-9}$ although some studies showed that their heights were normal ${ }^{810} 11$ or that they were shorter. ${ }^{12-14}$ These discrepancies may be due to the difficulty in obtaining exactly matched control groups. When comparing heights the groups must be accurately matched for social class, racial origin, and parental height. The ideal control for a diabetic child is his unaffected identical twin, as twins usually grow at the same rate and to the same final height. ${ }^{15}$

We studied the heights of identical twins discordant for insulin dependent diabetes at the time of diagnosis of the diabetic twin in order (a) to determine whether the diabetic was taller or shorter at diagnosis than his unaffected cotwin and $(b)$, if there was a difference, to estimate how long before diagnosis growth had been affected.

\section{Subjects and methods}

We studied identical twins included in the King's College Hospital survey. Monozygosity was established as described.16
Diabetic Department, King's College Hospital, London SE5 9RS P J HOSKINS, MRCP, MRC research fellow

R D G LESLIE, MD, MRCP, Welloome Trust senior fellow and consultant

Correspondence and requests for reprints to: $\mathrm{Dr} \mathrm{D}$ A Pyke. 
A sample of twin pairs discordant for insulin dependent diabetes were separated into two groups-group 1, pairs in whom the diabetic twin was diagnosed during the growth years (under 19); and group 2, pairs in whom the diabetic was diagnosed at age 25 or more-that is, after growth had stopped-who served as a control for observer or apparatus error in height measurement. Pairs with a history of major antecedent illness were excluded (none in group 1, three in group 2).

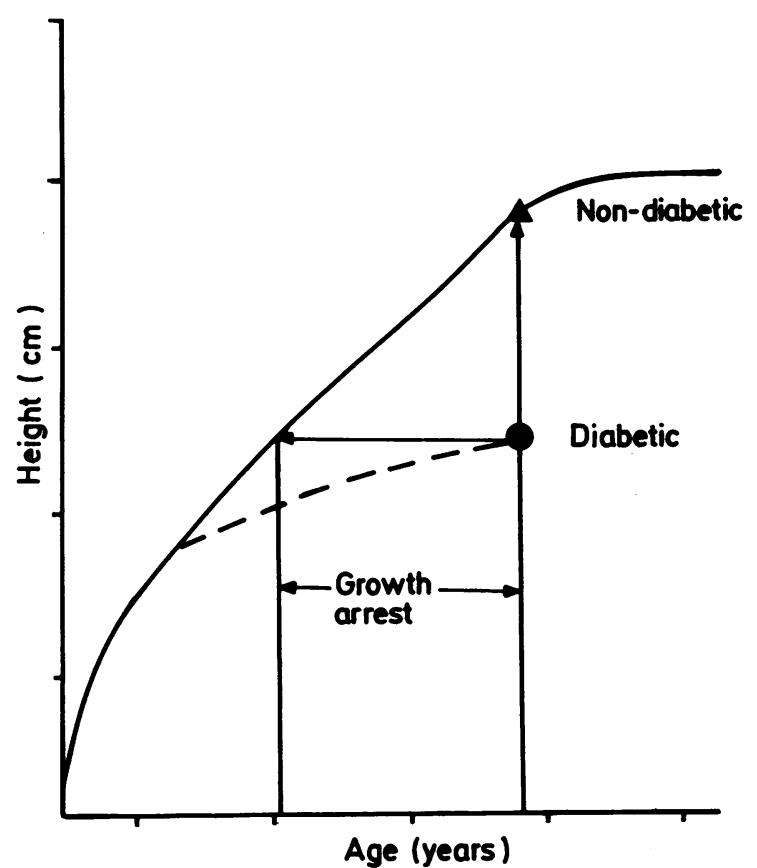

Method for conversion of height difference found between identical cotwins at diagnosis into period of growth arrest.

Heights of both cotwins at diagnosis of diabetic twin are plotted on Tanner and Whitehouse growth chart (illustrated schematically). Both twins should be growing along same centile line as illustrated by line labelled "non-diabetic." Diabetic, however, is shorter. We extrapolate back to unaffected twin's centile line to find when growth was arrested. Period would be longer if growth was delayed, not arrested (dashed line).

All the cotwins in group 1 were living together at the time the diabetic was diagnosed.

In group 143 pairs were available for study, but in only 16 pairs was the height of both twins recorded at the time of diagnosis of the diabetic. In group 217 pairs were available for study; we had the final heights of both cotwins in all these pairs.

Height at diagnosis-The height of both cotwins at the time of diagnosis of the diabetic in group 1 either came from our own records (four pairs) or was provided by their referring physician (12 pairs). Heights were measured to the nearest quarter of an inch $(6 \mathrm{~mm})$, and for each pair height was estimated by the same observer on the same occasion. A measuring scale fixed to the wall with a mobile arm was used to make the measurements. Final adult heights were used in group 2, and the information came from our own records in all 17 pairs.

Duration of growth arrest before diagnosis-Identical twins are usually the same height. ${ }^{15}$ The mean height difference between healthy identical cotwins is less than $2 \mathrm{~cm} .^{15}$ Thus if a diabetic is appreciably shorter than his unaffected cotwin at the time of diagnosis of diabetes his growth must have been affected some time before. The duration of growth arrest or delay which this height difference represents may be estimated by plotting the heights of both cotwins at the time of diagnosis of the diabetic twin on a Tanner and Whitehouse growth chart (see figure). The diabetic should be growing along the same centile line as his twin. If he is shorter at diagnosis than his cotwin we can estimate when growth was first affected by extrapolating back to the unaffected twin's centile line. This assumes that growth has stopped; if growth was reduced rather than arrested the period would be longer.

Birth weight information was obtained from the parents.

Statistics-Results are given as means and SEM. Fisher's exact test and Student's $t$ test for paired samples were used; $p<0.05$ was considered significant.

\section{Results}

Height at diagnosis-In none of the 16 pairs in group 1, in which the diabetic was diagnosed under the age of 19 , was the diabetic taller (table I). Eight diabetic twins were shorter than their nondiabetic cotwin, and in the remainder the cotwins were the same height. In the eight diabetics who were shorter at diagnosis the mean difference was 3.4 (SEM 0.62$) \mathrm{cm}$ (range 1.3 to $7.1 \mathrm{~cm}$ ). The mean difference for all 16 twin pairs was $1.7(0.54) \mathrm{cm}$. By contrast, in group 2 , in which the diabetic was diagnosed over the age of 25 , the diabetic was taller than his unaffected cotwin in five pairs, the same height in six, and shorter in six (table I). The mean difference in height (unaffected twin minus diabetic cotwin) was negligible $(0.08$ $($ SEM 0.3$) \mathrm{cm}$ ). Thus in the 16 twin pairs aged less than 19 the diabetic was never taller than his non-diabetic cotwin, whereas of those aged 25 or more years at diagnosis five out of 17 were taller (Fisher's exact test: $\mathrm{p}=0.026$ ).

Duration of growth arrest and symptoms in group 1-The mean duration of growth arrest in seven of the eight diabetics who were shorter at diagnosis was 35 weeks (range 21 to 68 ; table II). (No

TABLE I-Height at diagnosis of diabetic twin compared with unaffected identical cotwin according to age at diagnosis

\begin{tabular}{ccccc}
\hline Group & $\begin{array}{c}\text { Age at } \\
\text { diagnosis } \\
\text { (years) }\end{array}$ & \multicolumn{3}{c}{ Height of diabetic twin at diagnosis } \\
\cline { 3 - 5 } & $4-18$ & Taller & Same & Shorter \\
\hline 1 & 25 & 0 & 8 & 8 \\
2 & $\geqslant 25$ & 5 & 6 & 6 \\
\hline
\end{tabular}

TABLE II-Diabetic identical twins diagnosed under 19 years (group 1)

\begin{tabular}{|c|c|c|c|c|c|}
\hline Twin No & $\begin{array}{c}\text { Age at } \\
\text { diagnosis } \\
\text { (years) }\end{array}$ & Sex & $\begin{array}{c}\text { Duration of } \\
\text { symptoms } \\
\text { (weeks) }\end{array}$ & $\begin{array}{l}\text { Height } \\
\text { difference* } \\
\text { (cm) }\end{array}$ & $\begin{array}{c}\text { Growth } \\
\text { delay } \\
\text { (weeks) }\end{array}$ \\
\hline $\begin{array}{l}1 \\
2 \\
3 \\
4 \\
5 \\
6 \\
7 \\
8\end{array}$ & $\begin{array}{r}14.3 \\
14.1 \\
12.6 \\
15.1 \\
11.1 \\
18.5 \\
10.9 \\
8.6\end{array}$ & $\begin{array}{l}\mathbf{F} \\
\mathbf{F} \\
\mathbf{F} \\
\mathbf{M} \\
\mathbf{M} \\
\mathbf{F} \\
\mathbf{M} \\
\mathbf{F}\end{array}$ & $\begin{array}{r}12 \\
2 \\
8 \\
2 \\
4 \\
8 \\
1 \\
12\end{array}$ & $\begin{array}{l}2.5 \\
1.3 \\
3.8 \\
3.8 \\
7.1 \\
2.5 \\
2.5 \\
4.0\end{array}$ & $\begin{array}{l}47 \\
17 \\
26 \\
31 \\
68 \\
+ \\
21 \\
26\end{array}$ \\
\hline Mean (SD) & & & $6.1(4.5)$ & $3.4(1.75)$ & $35(17 \cdot 6)$ \\
\hline $\begin{array}{r}9 \\
10 \\
11 \\
12 \\
13 \\
14 \\
15 \\
16\end{array}$ & $\begin{array}{r}4.1 \\
4.6 \\
5.3 \\
14.5 \\
4.4 \\
12.1 \\
15.4 \\
16.6\end{array}$ & $\begin{array}{l}\mathbf{M} \\
\mathbf{F} \\
\mathbf{F} \\
\mathbf{M} \\
\mathbf{M} \\
\mathbf{F} \\
\mathbf{M} \\
\mathbf{F}\end{array}$ & $\begin{array}{l}4 \\
4 \\
4 \\
1 \\
4 \\
3 \\
4 \\
2\end{array}$ & $\begin{array}{l}0 \\
0 \\
0 \\
0 \\
0 \\
0 \\
0 \\
0\end{array}$ & $\begin{array}{l}\text { None } \\
\text { None } \\
\text { None } \\
\text { None } \\
\text { None } \\
\text { None } \\
\text { None } \\
\text { None }\end{array}$ \\
\hline
\end{tabular}

*Height of unaffected twin minus height of diabetic.

†No estimate made. Diagnosis of diabetes made towards end of adolescence when growth very slow. Therefore any small measurement error would give large error in estimation of duration of growth delay, making estimate unreliable.

estimate of growth arrest was made in pair No 6 (see table II).) By contrast, the average duration of symptoms was only six weeks (range one to 12). In all cases the duration of growth arrest was considerably longer than the duration of symptoms. The difference would have been even greater if there had been growth delay instead of growth arrest. One of the non-diabetic cotwins (pair 5) later developed insulin dependent diabetes. His growth velocity fell from $6.1 \mathrm{~cm} /$ year (95th centile) 12 months before diagnosis to $4.1 \mathrm{~cm} /$ year (10th centile) two months before diagnosis despite a normal oral glucose tolerance test result; this indicates that growth delay rather than arrest was the most likely mechanism.

Growth arrest and age-Within group 1 growth arrest was more common in those diabetics aged 10 to 19 at diagnosis, being present in seven of 11, than in those aged 4 to 9 , of whom only one of five showed arrest. This difference, however, was not statistically significant (Fisher's exact test: $p=0 \cdot 128$ ).

Sex-Growth arrest was equally common in boys and girls (see table II).

Birth weight-Except in pair 5, in twins diagnosed under the age of 19 the mean birth weights of the diabetic and non-diabetic cotwins were similar (2.4 (SEM 0.125) $v 2.3(0.1) \mathrm{kg})$; in pair 5 the diabetic 
was lighter $(1.3 v 2.8 \mathrm{~kg})$. Nevertheless, the parents of this pair reported that their heights were similar in early childhood.

Birth order-Among twins diagnosed under 19 the diabetic was born first in three of eight pairs with growth arrest and in four of eight pairs not showing growth arrest.

\section{Discussion}

These observations suggest that, contrary to the widely accepted belief, young diabetics are not taller than expected at diagnosis ${ }^{2-9}$ : half of our diabetics were shorter than their unaffected cotwin and the remainder were the same height. This is the first study in which the unaffected identical cotwin of a diabetic child has served as the control and thus the first report in which the diabetic and control have been adequately matched.

For accurate recording of absolute heights a Harpenden Stadiometer should be used. That it was not used in our study does not, we think, invalidate our conclusions, because both cotwins of a pair were measured on the same occasion using the same apparatus; furthermore, we were interested in differences in height not absolute heights. Any error in measurement might have occurred with an equal chance in either twin, which would not lead to bias in the results. The validity of this argument is confirmed by the twin pairs diagnosed over the age of 25, in whom growth had stopped long before the diagnosis of diabetes. In this group the diabetic was as often taller, shorter, or the same height as his unaffected cotwin and the mean difference between cotwins was negligible. Thus our results are unlikely to be due to errors in measurement.

There are many causes of growth retardation. In this study twins with any history of major antecedent illness other than diabetes were excluded and there was no evidence of physical or psychological deprivation in the diabetic twin. Genetic factors were irrelevant, as we were comparing identical twins, and congenital influences were unlikely, as, with one exception, birth weights were similar in cotwins. We therefore believe that the growth delay that we found was related to the diabetes.

Growth delay may be due to the metabolic abnormalities associated with diabetes. Before the discovery of insulin diabetic children stopped growing, ${ }^{1}$ and it is still true that after diagnosis the growth of diabetic children may be reduced." This is believed to be due to poor diabetic control. ${ }^{17}$ Alternatively, a common pathogenetic mechanism may independently cause both growth delay and diabetes-for example, antibodies to pancreatic islet, ${ }^{18}$ thyroid, ${ }^{19}$ and pituitary ${ }^{20}$ tissue are found in newly diagnosed insulin dependent diabetics, and these may influence growth. We were unable to determine the mechanism of growth delay.

Growth arrest in this study was related to age at diagnosis; of those diagnosed between 4 and 9 years, only one of five showed growth arrest compared with seven of 11 diagnosed between 10 and 19 years. If this difference was true and not merely due to our small numbers, then the onset of diabetes in the young may be more rapid (and we note that the duration of symptoms was longer, though not significantly so, in those who showed growth delay than in those who did not-6.1 $v 3.2$ weeks). An alternative explanation is that the difference was due to the age related difference in growth velocity. Growth is rapid in early childhood and during puberty but relatively slow in the intervening years. The more rapid the growth, the more sensitive will it be to any retarding influence.

In those diabetics who were shorter at diagnosis than their unaffected cotwins growth was affected for an average of at least 29 weeks before the appearance of symptoms. If growth had not been arrested but only delayed then this period must have been even greater. We believe that diabetes is more likely to cause growth delay than growth arrest, and this hypothesis is supported by our observations on one twin who showed growth delay with normal glucose tolerance shortly before he developed insulin dependent diabetes. Decrease in growth velocity may be a marker for the future development of diabetes in genetically susceptible subjects.

We believe that this study gives the first definitive evidence for a clinical abnormality preceding the onset of symptoms of diabetes and confirms that insulin dependent diabetes may be a disease of relatively slow onset. ${ }^{21-28}$

We thank all the physicians who referred the twins and provided information about them.

\section{References}

1 Joslin EP, Root HF, White P. The growth, development and prognosis of diabetic

2 Ladd WS, Ray CS. Growth in children with diabetes mellitus. Am $\mathcal{f}$ Dis Child 1926;32:812-38.

Boyd JD, Nelson MV. Growth studies of children with diabetes mellitus. Am I Dis Child 1928;35:753-61.

4 Fischer $\mathrm{AE}$, Mackler HS, Marks HH. Long term growth of diabetic children.

5 White $\mathcal{F}$. The potential diabetic child. JAMA 1927;88:170-1.

Craig JO. Growth as a measurement of control in the management of diabetic children. Postgrad Med 3 1970;46(suppl):607-10.

Pond H. Some aspects of growth in diabetic children. Postgrad Med $\mathcal{F} 1970 ; 46$

Drayer NM. Height of diabetic children at onset of symptoms. Arch Dis Child $1974 ; 40: 616-20$.

9 Edelstein AD, Hughes IA, Oakes S, Gordon IRS, Savage DCL. Height and skeletal maturity in children with newly diagnosed juvenile onset diabetes. Arch Dis Child $1981 ; 56: 40-4$.

10 Beal CK. Body size and growth rate of children with diabetes mellitus. $f$ Pediatr

11 Jivani SKM, Rayner PHW. Does control influence the growth of diabetic children? Arch Dis Child 1973;48:109-15.

12 Jackson RL, Kelly HG. Growth of children with diabetes mellitus in relation

13 Hamne B. Growth in a series of diabetic children on identical treatment with free diet and insulin, 1944-1960. Acta Paediatr Scand 1962;51(suppl 135): $72-8$.

14 Danowski TS. Diabetes mellitus with emphasis on children and young adults. Baltimore: Williams and Wilkins, 1957.

15 Fischbein S. Intra-pair similarity in physical growth of monozygotic and of dizygotic twins during puberty. Ann Hum Biol 1977; 4:417-30

16 Barnett AH, Eff C, Leslie RDG, Pyke DA. Diabetes in identical twins. A study of 200 pairs. Diabetologia 1981;20:87-93.

iliams ML, Savage DCL. Glycosylated haemoglobin levels in children with

18 Brogren CH, Lernmark A. Islet cell antibodies in diabetes. Clin Endocrinol Metab 1982;11:409-30.

19 Riley WJ, Maclaren NK, Lezotte DC, Spiller KP, Rosenbloom AL. Thyroid autoimmunity in insulin dependent diabetes mellitus: the case for routine screening. $\mathcal{F}$ Pediatr 1981 ; $88: 350-4$.

20 Mirakian R, Cudworth AG, Bottazzo GF, Richardson CA, Doniach D. Autoimmunity to anterior pituitary cells and the pathogenesis of insulin dependent diabetes mellitus. Lancet 1982 ; i :755-8.

21 Srikanta S, Ganda OP, Eisenbarth GS, Soeldner JS. Islet cell antibodies and beta cell function in monozygotic triplets and twins in

22 Srikanta S, Ganda OP, Jackson RA, et al. Type 1 diabetes mellitus in monozygotic twins: chronic progressive beta cell dysfunction. Ann Intern Med 1983; 80:320-6.

23 Gorsuch AN, Spencer KM, Lister J, et al. Evidence for a long pre-diabetic period in type 1 (insulin-dependent) diabetes mellitus. Lancet 1981 ;ii:1363-5.

(Accepted 23 October 1984)

\section{Correction}

Is there a place in the United Kingdom for intensive antacid treatment for chronic peptic ulceration?

An error occurred in this paper by Dr R Faizallah and others (6 October 1984 p 869). The authors write: "A reader has pointed out that in table II the $x^{\text {" }}$ values for treatment are not adjusted for dose. If this is done the values for 4 weeks and 8 weeks become 5.09 and 1.77 respectively. The p values and conchusions of the paper are not affected." 